\section{OPEN ACCESS}

Edited by:

Roger M. Bourne,

University of Sydney, Australia

Reviewed by:

Piotr Kozlowski,

University of British Columbia, Canada Laurence Gluch,

The Strathfield Breast

Centre, Australia

*Correspondence:

Ghulam Nabi

g.nabi@dundee.ac.uk

Specialty section:

This article was submitted to

Cancer Imaging and Image-directed

Interventions,

a section of the journal

Frontiers in Oncology

Received: 07 May 2019

Accepted: 13 June 2019

Published: 09 July 2019

Citation:

Wei C, Zhang Y, Malik H, Zhang X,

Alqahtani $S$, Upreti $D$

Szewczyk-Bieda M, Lang S and

Nabi G (2019) Prediction of

Postprostatectomy Biochemical

Recurrence Using Quantitative

Ultrasound Shear Wave Elastography

Imaging. Front. Oncol. 9:572.

doi: 10.3389/fonc.2019.00572

\title{
Prediction of Postprostatectomy Biochemical Recurrence Using Quantitative Ultrasound Shear Wave Elastography Imaging
}

\begin{abstract}
Cheng Wei ${ }^{1}$, Yilong Zhang ${ }^{2}$, Hamza Malik', Xinyu Zhang ${ }^{3}$, Saeed Alqahtani ${ }^{1,4}$, Dilip Upreti ${ }^{1}$, Magdalena Szewczyk-Bieda ${ }^{5}$, Stephen Lang ${ }^{6}$ and Ghulam Nabi ${ }^{1 *}$
\end{abstract}

${ }^{1}$ Division of Imaging Science and Technology, School of Medicine, Ninewells Hospital, University of Dundee, Dundee, United Kingdom, ${ }^{2}$ School of Science and Engineering, University of Dundee, Dundee, United Kingdom, ${ }^{3}$ Division of Population Health and Genomics, School of Medicine, University of Dundee, Dundee, United Kingdom, ${ }^{4}$ Department of Radiological Sciences, College of Applied Medical Science, Najran University, Najran, Saudi Arabia, ${ }^{5}$ Department of Clinical Radiology, Ninewells Hospital, Dundee, United Kingdom, ${ }^{6}$ Department of Pathology, Ninewells Hospital, Dundee, United Kingdom

Objectives: To determine the prognostic significance of tissue stiffness measurement using transrectal ultrasound shear wave elastography in predicting biochemical recurrence following radical prostatectomy for clinically localized prostate cancer.

Patients and Methods: Eligible male patients with clinically localized prostate cancer and extraperitoneal laparoscopic radical prostatectomy between November 2013 and August 2017 were retrospectively selected. Information of potential biochemical recurrence predictors, including imaging (ultrasound shear wave elastography and magnetic resonance imaging), clinicopathological characteristics, and preoperative prostate specific antigen (PSA) levels were obtained. Recurrence-free survival (KaplanMeier curve) and a multivariate model were constructed using Cox regression analysis to evaluate the impact of shear wave elastography as a prognostic marker for biochemical recurrence.

Results: Patients experienced biochemical recurrence in an average of $26.3 \pm$ 16.3 months during their follow-up. A cutoff of $144.85 \mathrm{kPa}$ for tissue stiffness measurement was estimated for recurrence status at follow-up with a sensitivity of $74.4 \%$ and a specificity of $61.7 \%$, respectively $(p<0.05)$. In univariate analysis, shear wave elastography performed well in all preoperative factors compared to biopsy Gleason Score, PSA and magnetic resonance imaging; in multivariate analysis with postoperative pathological factors, shear wave elastography was statistically significant in predicting postoperative biochemical recurrence, which improved the C-index of predictive nomogram significantly $(0.74$ vs. $0.70, p<0.05)$.

Conclusions: The study revealed that quantitative ultrasound shear wave elastography-measured tissue stiffness was a significant imaging marker that enhanced the predictive ability with other clinical and histopathological factors in prognosticating postoperative biochemical recurrence following radical prostatectomy for clinically localized prostate cancer.

Keywords: prostate cancer, radical prostatectomy, biochemical recurrence, ultrasound shear wave elastography, nomogram 


\section{INTRODUCTION}

The primary goal of biomarker/predictive test research in the field of prostate cancer ( $\mathrm{PCa}$ ) is to increase the prediction rate of postoperative outcome and/or biochemical recurrence (BCR). Radical prostatectomy (open or minimally invasive) is an established treatment option for clinically localized PCa. Thirty to forty percent of men show postoperative BCR and require further adjuvant or salvage treatments on follow-up $(1,2)$. Predicting recurrence would be useful in setting up personalized treatment plans for patients, as well as selecting men for adjuvant treatment following prostatectomy. An improved method of predicting recurrence can help in reducing overtreatment of $\mathrm{PCa}$ recurrence and thereby reducing side effects and improve quality of life.

There are several known predictors for BCR following surgical therapy for $\mathrm{PCa}$ published in the literature, e.g., age, prostate specific antigen (PSA), biopsy Gleason Score (bGS), clinical stage, pathology Gleason Score (pGS), and other postoperative data (3); however, ultrasound imaging, specifically ultrasound

TABLE 1 | Characteristics of recurrence and non-recurrence patients.

\begin{tabular}{|c|c|c|c|}
\hline & Total & Recurrence & Non-recurrence \\
\hline No. of patients & 209 & 45 & 164 \\
\hline Age (years), mean $\pm S D$ (range) & $66 \pm 4.92(53-76)$ & $66 \pm 5.20(59-76)$ & $66 \pm 4.87(53-76)$ \\
\hline Preoperative PSA level $(\mathrm{ng} / \mathrm{ml})$, mean \pm SD (range) & $11.26 \pm 7.48(0.1-47.7)$ & $14.21 \pm 9.81(2-47.7)$ & $10.49 \pm 6.56(0.1-47)$ \\
\hline PSA density $\left(\mathrm{ng} / \mathrm{ml}^{2}\right)$, mean $\pm \mathrm{SD}$ (range) & $0.19 \pm 0.15(0.001-1.11)$ & $0.26 \pm 0.20(0.05-1.11)$ & $0.17 \pm 0.12(0.001-0.92)$ \\
\hline \multicolumn{4}{|l|}{ Gleason score at biopsy } \\
\hline $4+3$ & $39(18.7 \%)$ & $8(3.8 \%)$ & $31(14.8 \%)$ \\
\hline $3+5$ & 7 (3.3\%) & $3(1.4 \%)$ & $4(1.9 \%)$ \\
\hline $4+4$ & 27 (12.9\%) & $9(4.3 \%)$ & $18(8.6 \%)$ \\
\hline $4+5$ & $17(8.1 \%)$ & $13(6.2 \%)$ & $4(1.9 \%)$ \\
\hline $5+3$ & $1(0.5 \%)$ & - & $1(0.5 \%)$ \\
\hline 3 & $17(8.1 \%)$ & $1(0.5 \%)$ & $16(7.7 \%)$ \\
\hline 4 & 45 (21.5\%) & $4(2 \%)$ & 41 (19.6\%) \\
\hline 5 & $131(62.7 \%)$ & 35 (17\%) & 96 (45.9\%) \\
\hline $\mathrm{N} / /^{*}$ & $8(3.8 \%)$ & $4(1.9 \%)$ & $4(1.9 \%)$ \\
\hline \multicolumn{4}{|l|}{ Surgical margin } \\
\hline Negative & $126(60.3 \%)$ & $11(5.3 \%)$ & $115(55.0 \%)$ \\
\hline Positive & 81 (38.7\%) & 32 (15.3\%) & 49 (23.4\%) \\
\hline $\mathrm{N} / \mathrm{I}$ & $2(1.0 \%)$ & $2(1.0 \%)$ & - \\
\hline \multicolumn{4}{|l|}{ Gleason Score after RP } \\
\hline $3+3$ & 5 (2.4\%) & - & 5 (2.4\%) \\
\hline $3+4$ & $101(48.3 \%)$ & $2(1.0 \%)$ & 99 (47.4\%) \\
\hline Positive & $16(7.7 \%)$ & $10(4.8 \%)$ & $6(2.9 \%)$ \\
\hline$N / I$ & $8(3.8 \%)$ & $4(1.9 \%)$ & $4(1.9 \%)$ \\
\hline \multicolumn{4}{|l|}{ Lymph node involvement } \\
\hline Negative & $186(89.0 \%)$ & 32 (15.3\%) & $154(73.7 \%)$ \\
\hline Positive & $10(4.8 \%)$ & $8(3.8 \%)$ & $2(1.0 \%)$ \\
\hline$N / I$ & $13(6.2 \%)$ & $5(2.4 \%)$ & $8(3.8 \%)$ \\
\hline
\end{tabular}

${ }^{*}$ No information. 
shear wave elastography (USWE), as imaging marker has not been reported.

Ultrasound imaging has been widely applied to guide transrectal and transperineal biopsies in the detection of $\mathrm{PCa}$ (4-6). USWE estimation of prostate tissue stiffness has been recently reported with promising diagnostic accuracy in both the detection and characterization of PCa (7-9). We have recently shown that the technology can reliably predict the grade of cancer and may provide essential information on the biology and microenvironment of the cancerous lesions. Moreover, USWE showed a very high diagnostic accuracy in predicting clinically significant PCa in men opting for radical prostatectomy $(10,11)$.

The aim of this study was to assess the predictive usefulness of USWE measured tissue stiffness in postprostatectomy BCR.

\section{MATERIALS AND METHODS}

\section{Study Population}

Between November 2013 and August 2017, 212 consecutive men opting for extraperitoneal radical prostatectomy as a treatment option for clinically localized PCa were selected. This was part of a prospective, protocol-driven study with prior ethical and institutional approval [Research Ethical Committee (REC) No. 13/ES/0099, and Research and Development No. 2012ON32] designed to assess the diagnostic accuracy of transrectal SWE ultrasound specifically for PCa. The basic demographic characteristics are presented in Table 1. Men were followed up postoperatively in clinics with PSA measurements every 3 months for the first year, 6-monthly for the second

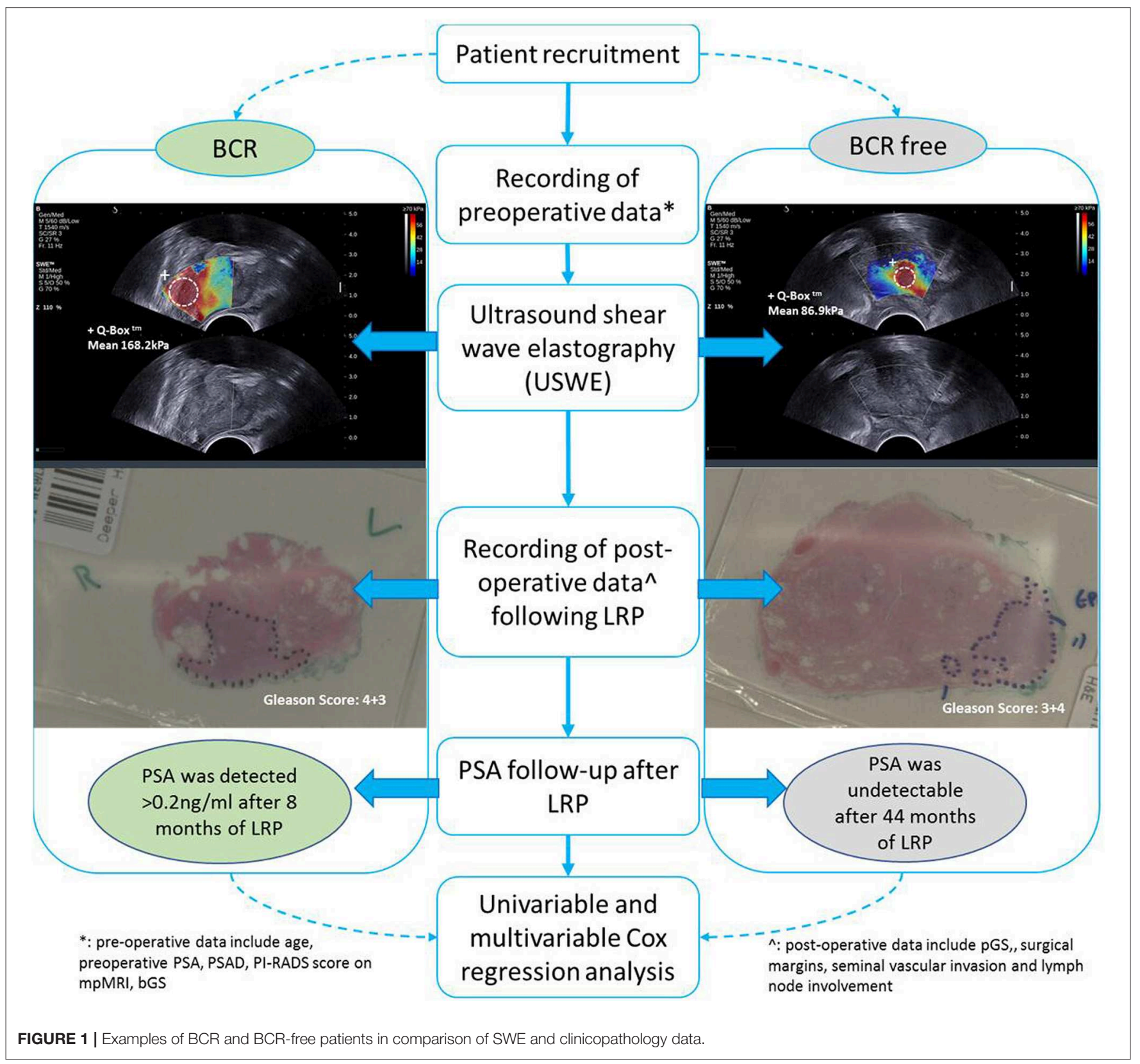


year, and once a year thereafter. A PSA of more than $0.2 \mathrm{ng} / \mathrm{ml}$ was considered as a cutoff for consideration of BCR, and this generated a request to discuss the case in multidisciplinary meeting for imaging and adjuvant/salvage treatment. The patient cohort was divided into two groups: BCR and BCR free groups as illustrated in Figure 1. PSA follow-up was recorded until April 2019, and the minimum follow-up for the recruited patients was 21 months.

\section{Clinicopathology Information}

All clinical data [age, weight, preoperative PSA and relative density (PSAD), PI-RADS score on multiparametric MRI (mpMRI), bGS, USWE], postoperative data [pGS, surgical margins (SM), seminal vascular invasion (SVI), lymph node involvement (LNI)], and clinical follow-up (months) were recorded. In all eligible patients, PSA fell to an undetectable level $(<0.1 \mathrm{ng} / \mathrm{ml})$ postoperatively. BCR was defined as any two consecutive PSA measurements $\geq 0.2 \mathrm{ng} / \mathrm{ml}$ detected during the follow-up (12).

\section{MR Protocol and PI-RADS Scoring}

MRI scan for each patient was carried out 6-8 weeks after the last biopsy with a 3-T scanner (TIM Trio, Siemens, Erlangen, Germany) to eliminate the artifacts due to blood clots caused by biopsy. Then, radical prostatectomy was usually done within 2 months (62 days targets) after MRI in this cohort. MRI protocol was derived from the European Society of Uro-radiology Guidelines (ESUR) 2012 (13) for PCa detection; acquisition parameters are shown and summarized in Table $2(10,11)$. All MR images were analyzed and scored by experienced uro-radiologists (SA, SMB) using PI-RADS v2.0; patients' clinicopathology data were blinded to both radiologists. Only suspicious lesions with PI-RADS score 3 and above were marked. Some of the patients' PI-RADS scores were not available because of inadequate sequences or poor images.

\section{USWE Imaging Protocol and Acquisition}

All USWE images were obtained using a transrectal endocavity transducer (SuperSonic Imagine, Aix en Provence, France) with patients being in either lithotomy or lateral position the day before the scheduled surgery. USWE mode was activated and prostate gland elastograms were obtained from cranial to caudal direction for each lobe of the prostate. All regions were scanned as described in our previous protocol (7). Briefly, each patient's prostate gland was scanned transrectally, and USWE images were acquired in transverse planes from base to apex with a gap of 4 to $6 \mathrm{~mm}$. The most suspicious lesions located in planes were rescanned in gaps as thin as $2-3 \mathrm{~mm}$ and reconstructed offline into $3-\mathrm{D}$ images. These suspicious areas were also examined by rotating transducers in different directions to confirm abnormalities and to perform measurements of their sizes. Three stiffness measurements of shear wave speed in $\mathrm{m} / \mathrm{s}$ or Young's modulus in $\mathrm{kPa}$ using pseudo-color map were obtained

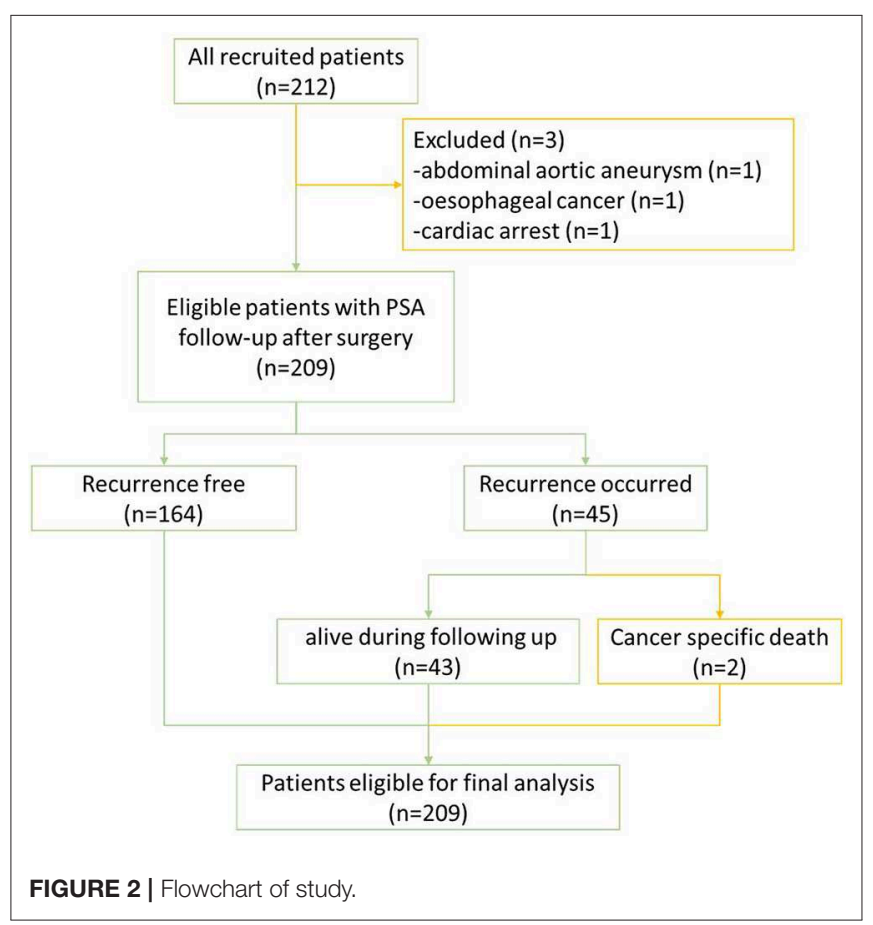

TABLE 2 | MRI acquisition parameters.

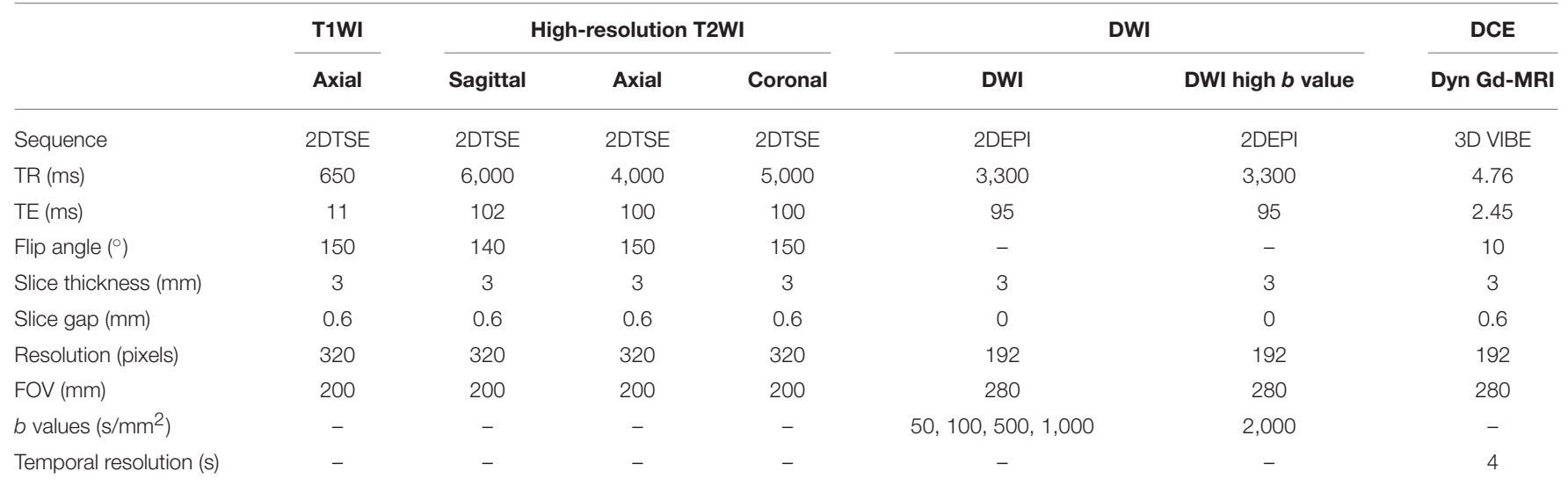



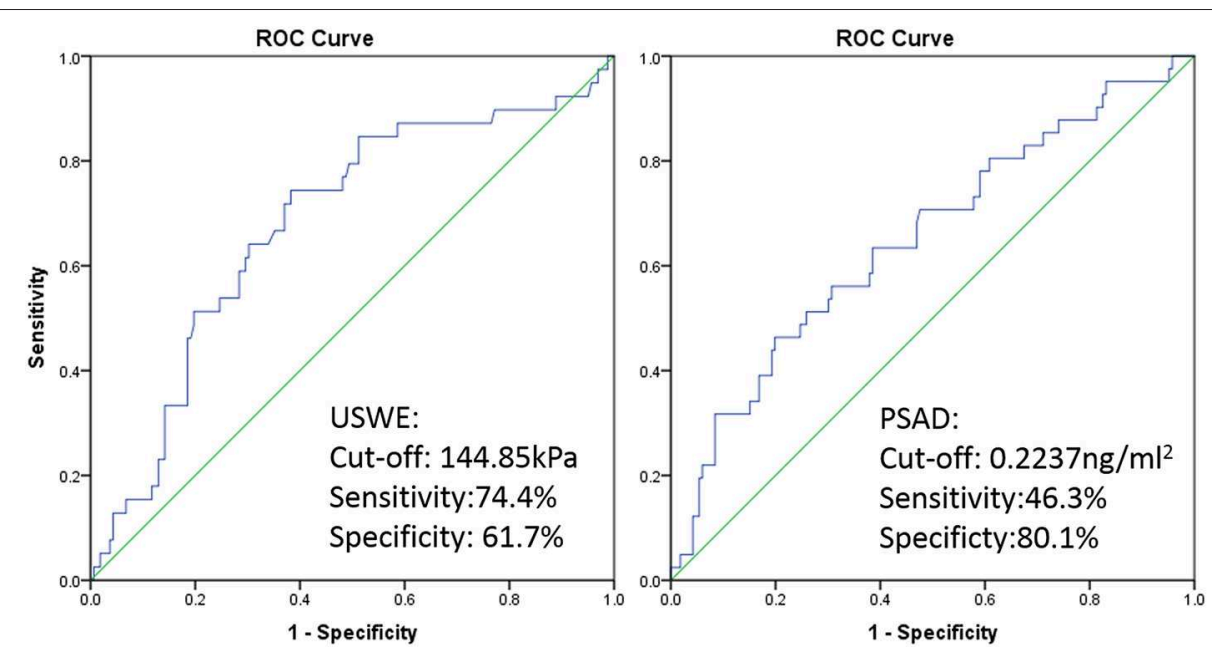

FIGURE 3 | ROC curve of USWE (left) and PSAD (right) for differentiating BCR and BCR free of PCa after radical surgery.

TABLE 3 | Cox univariate and multivariate analyses.

\begin{tabular}{|c|c|c|c|c|c|}
\hline & & \multicolumn{2}{|c|}{ Univariate } & \multicolumn{2}{|c|}{ Multivariate } \\
\hline & Weight & 0.990 (0.978-1.003) & 0.119 & & \\
\hline & SWE & & & & \\
\hline & $\leq 144.85$ & 1 (referent) & - & 1 (referent) & - \\
\hline & $\leq 7$ & 1 (referent) & - & 1 (referent) & - \\
\hline & $>7$ & 3.919 (2.119-7.248) & $<0.001$ & $2.304(1.207-4.398)$ & 0.011 \\
\hline & PSA level (ng/ml) & & & & \\
\hline & $\leq 14.45$ & 1 (referent) & - & 1 (referent) & - \\
\hline & $>14.45$ & $2.954(1.576-5.538)$ & $<0.001$ & & \\
\hline & PI-RADS & & & & \\
\hline & $\leq 3$ & 1 (referent) & - & 1 (referent) & - \\
\hline & $>3$ & $2.856(0.688-11.855)$ & 0.148 & & \\
\hline \multirow[t]{7}{*}{ Postoperative parameters } & Surgical margin & & & & \\
\hline & Neg & 1 (referent) & - & 1 (referent) & - \\
\hline & Pos & $4.930(2.468-9.848)$ & $<0.001$ & $2.383(1.136-4.999)$ & 0.022 \\
\hline & Vascular invasion & & & & \\
\hline & Neg & 1 (referent) & - & 1 (referent) & - \\
\hline & Pos & $6.020(2.914-12.434)$ & $<0.001$ & 2.798 (1.236-6.333) & 0.014 \\
\hline & Gleason Score at RP & & & & \\
\hline
\end{tabular}


by three researchers (GN, CW, and DU) independently. The ratio between abnormal and normal areas was also recorded.

\section{Statistical Analyses}

In this paper, BCR as an outcome was a patient-based analysis and hence major predominant and highest histological grade was used. There could be multiple lesions for each patient and lesion-based analysis has been published by our research group previously $(10,11)$. Baseline characteristics and pathological outcomes were compared using the chi-square test for categorical data and the Student's $t$-test or ANOVA for continuous data. Receiver operator characteristic (ROC) curves were plotted for stiffness values followed by application of maximum Youden index (sensitivity-[1-specificity]), indicating that sensitivity and specificity were equally important to determine optimal cutoff values between BCR and BCR-free patients (14). Univariate and multivariate Cox regression analyses were used to identify factors predictive of BCR. Analyses were performed using SPSS 22 (IBM Corporation, New York, USA). The alpha level was set at 0.05 to determine two-tailed significance. The predicting outcome was evaluated in nomograms and plotted in $\mathrm{R}$ 4.4.1. The values of concordance indexes (C-index) were calculated and compared.

\section{RESULTS}

Of all 212 patients, 3 patients were excluded due to death from other diseases during follow-up; the remaining 209 patients eligible for final analysis including 2 patients with PCa-specific deaths (treated as BCR patients) are illustrated in Figure 2. The mean age of the cohort was $66 \pm 4.95$ years with a mean preoperative PSA of $11.50 \pm 7.63 \mathrm{ng} / \mathrm{ml}$ (range: $0.1-47.7$ ). Of all the eligible patients, $45(45 / 209 ; 21.5 \%)$ experienced BCR in an average of $26.3 \pm 16.3$ months (range: 3-66) during their follow-up with 25 patients for salvage radiotherapy and 18 patients for hormones therapy. Almost a fifth of participants' biopsy results were GS 6 (39/209, 18.7\%), but only 5 (5/209; 2.4\%) remained as GS 6 disease on histopathology of radical prostatectomy, suggesting a significant upgrading of disease on surgical resection (Table $\mathbf{1}$ ).

ROC curve was plotted and a cutoff value of $144.85 \mathrm{kPa}$ was calculated with the highest combination of sensitivity and specificity, patients with BCR had $74.4 \%$ possibility of cancer stiffness value above $144.85 \mathrm{kPa}$ (sensitivity), and patients with BCR free had a $61.7 \%$ possibility of cancer stiffness value below $144.85 \mathrm{kPa}$ (specificity, $p<0.05$ ). The cutoff value for preoperative PSAD level differentiating BCR and BCR-free groups was $0.2237 \mathrm{ng} / \mathrm{ml}^{2}$ with a sensitivity and specificity of 46.3 and $80.1 \%$, respectively ( $p<0.05$, Figure 3 ).

On univariate analysis, preoperative PSA level, PSAD, bGS, and USWE were all significantly associated with $\operatorname{BCR}(p<$ $0.05)$. Age, weight, and mpMRI using PI-RADS v2 classification without showing any significance $(p>0.05)$ were excluded for further analyses. In the postoperative analysis, pGS was significant in comparison to other parameters in predicting $\mathrm{BCR}$

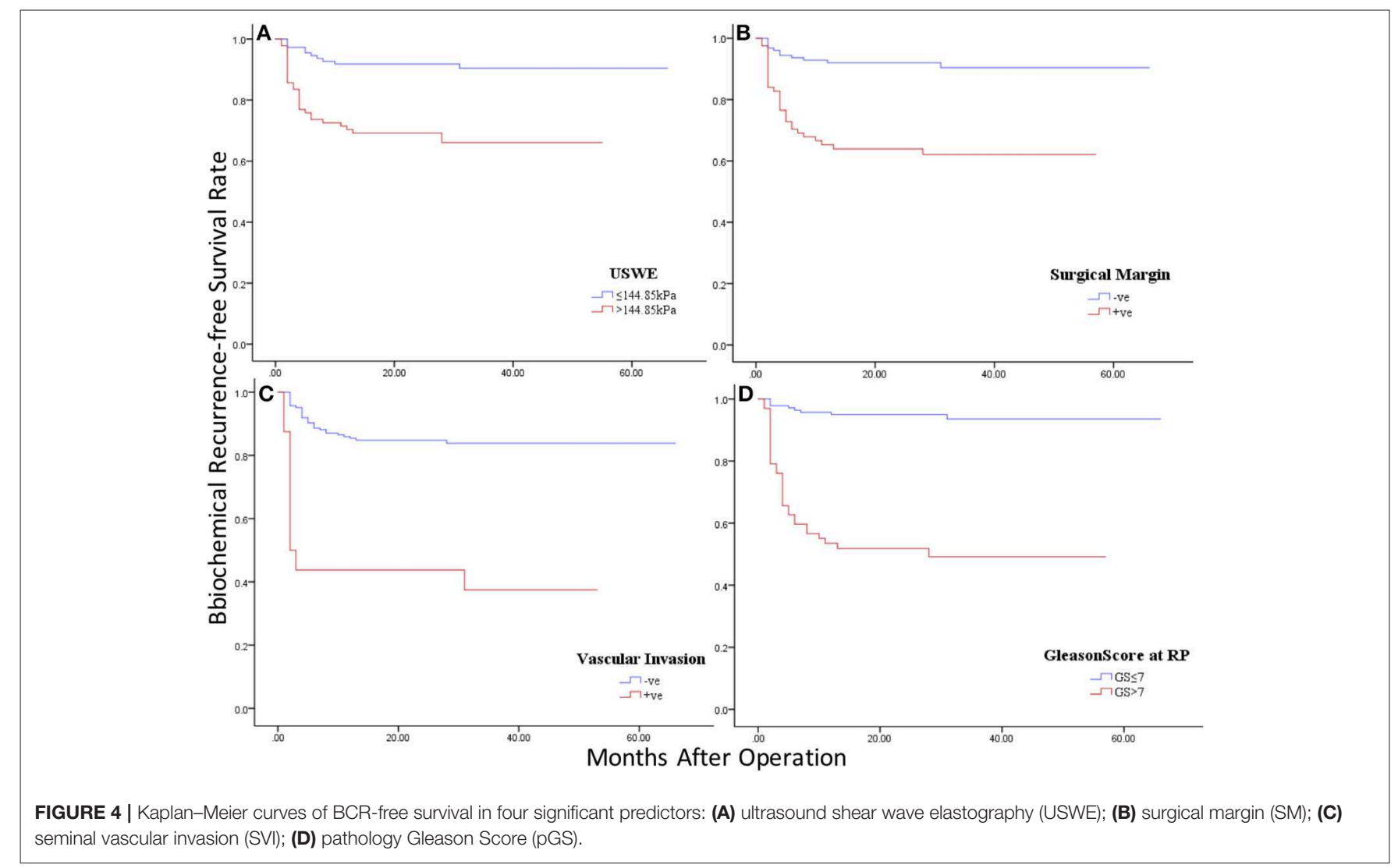


with the highest hazard ratio (HR) of 11.293. Multivariable Cox regression analysis showed the remaining variables excluding LNI $(p=0.529)$ to be statistically significant and independently predictive of BCR $(p<0.05$, Table 3$)$.
Figure 4 showed Kaplan-Meier survival analysis of BCRfree survival for the four significant predictors including the only preoperative parameter USWE and three postoperative parameters: SM, SVI, and pGS.

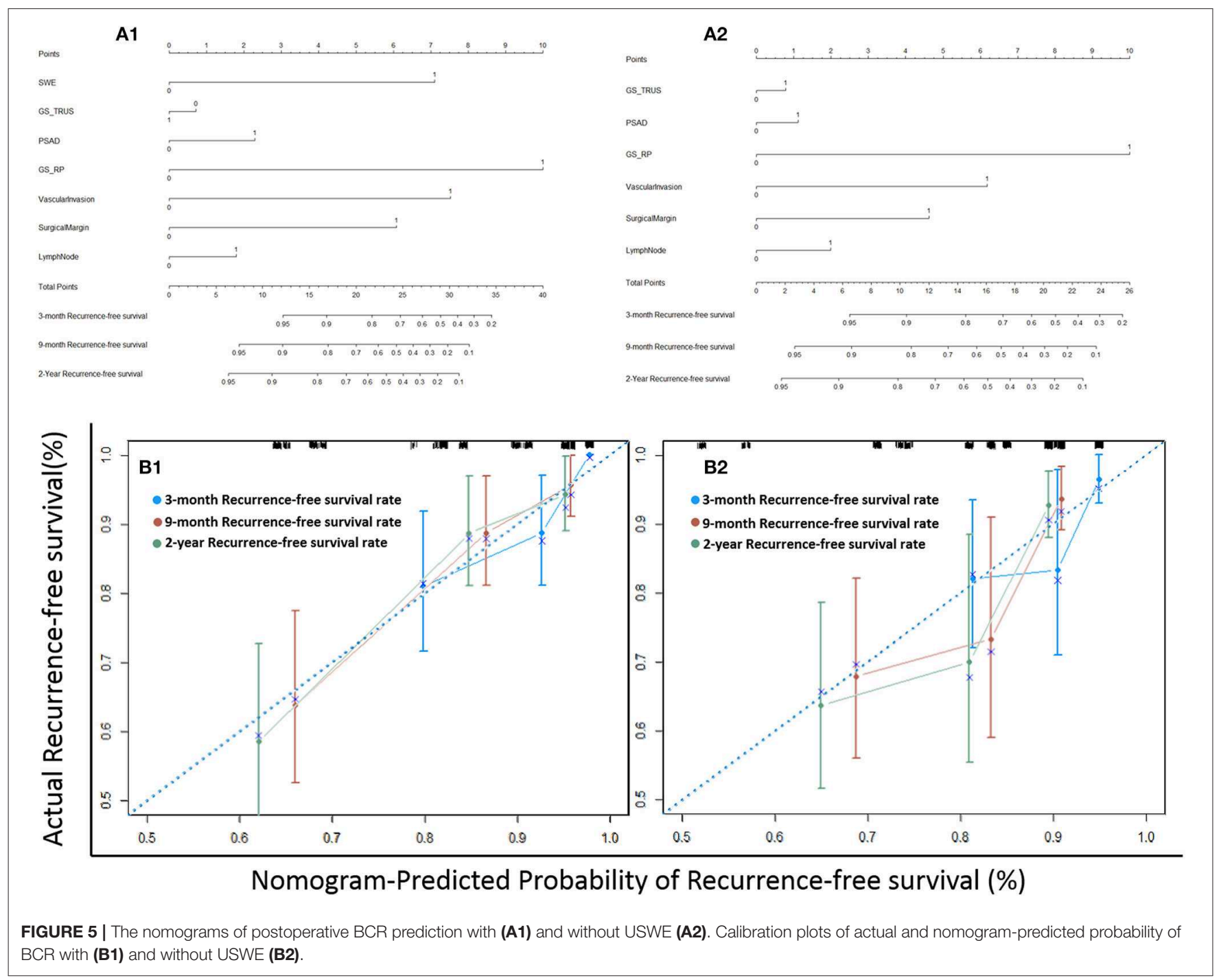

TABLE 4 | Literature review and comparison between previous and current studies.

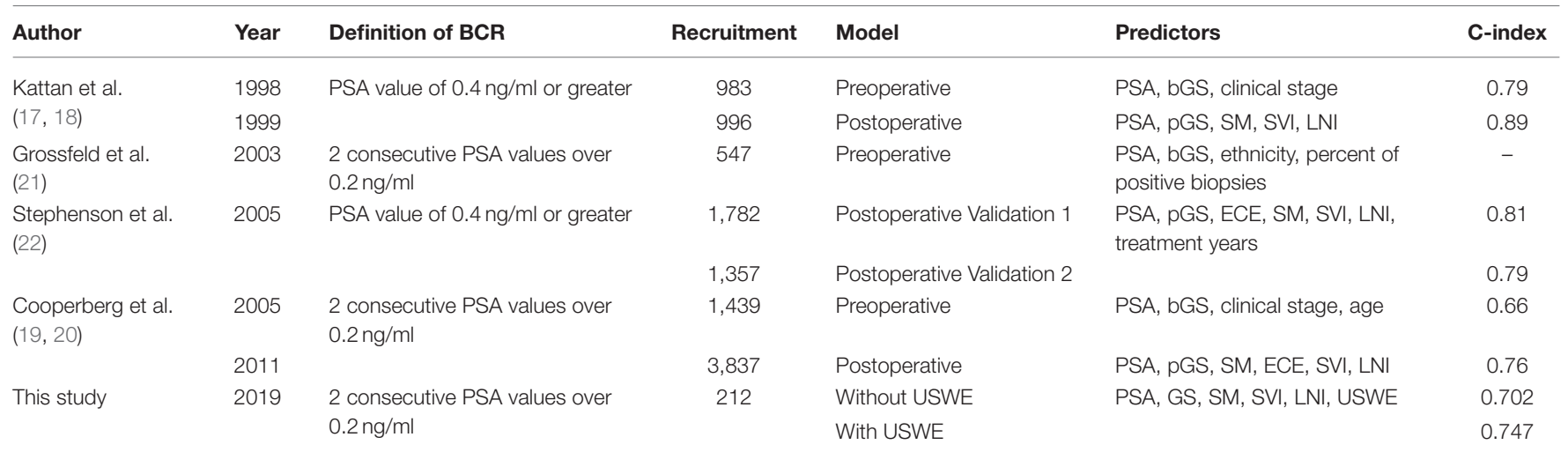


Figures 5A1,A2 showed the nomograms constructed for BCR with and without USWE data. Longer scales indicated a higher percentage of impact and larger points were followed by shorter BCR survival. The pGS had the greatest impact followed by USWE and SVI. USWE was the only preoperative factor with a significant impact on BCR-free survival. The C-index of the established nomogram that had USWE variate to predict the recurrence-free survival of patients in the cohort was significantly higher than that of the nomogram without USWE $\{0.747$ [95\% confidence interval (CI), $0.670-0.824$ ] vs. 0.702 [ $95 \%$ CI, $0.625-$ $0.779], p<0.05\}$. The nomograms were then internally validated using 100 bootstrap samples; internal calibration curves were shown in Figures 5B1,B2.

\section{DISCUSSION}

To our knowledge, this was the first report to predict BCR with a non-histopathological independent imaging markerUSWE. Clinical and histopathological variables on multivariate analysis have all been previously reported. Introducing USWE into nomograms for PCa BCR with other clinical, pathological, and radiological parameters have increased the accuracy of BCR prediction $(0.747$ vs. 0.702$)$.

Previous published studies have reported USWE to have a high diagnostic accuracy in clinical staging and localization of tumors within prostate glands of men suspected of PCa $(6,7,10,11,15,16)$. Our findings in this study add to the existing knowledge and show that measurement of stiffness in $\mathrm{kPa}$ increase $\mathrm{BCR}$ prediction ability of clinicopathological parameters.

In this study, the USWE stiffness value was able to distinguish BCR and BCR-free sub-cohort populations as shown in the first ROC curve (Figure 3, left), and then using Youden analysis (14), cancers' stiffness cutoff value $144.85 \mathrm{kPa}$ in Young's modulus was higher in our study in comparison to the number of other reports in diagnosing cancer, but this was defined with the highest combination of sensitivity and specificity, and a larger number of high-grade cancers might have influenced this cutoff value. In this study, we have then added this figure to other clinical and histopathological biomarkers in nomograms for BCR prediction (Figure 5).

Previous studies have analyzed the importance of preoperative and postoperative data in predicting BCR. Kattan et al. $(17,18)$ and Cooperberg et al. $(19,20)$ analyzed both data and found that postoperative $\mathrm{C}$-index values were higher than preoperative values ( 0.89 vs. $0.79,0.76$ vs. 0.66 ). Grossfeld et al. (21) found PSA levels, bGS, and percentage of biopsy cores involved by cancer tissue to be significant preoperative predictors of BCR. Stephenson et al. (22) validated two groups of patients and had summarized similar postoperative C-index value ( 0.81 vs. 0.79 ). Ozden et al. (23) recruited 305 patients and concluded that age was not a significant factor to predict BRC, which was similar to our study. Freedland et al. (24) found that the percentage of biopsy cores involvement by cancer was a better predictor than the number of cores involved by cancer. Similar to these studies, in our observation, PSA and bGS were both significantly important predictors of $\mathrm{BCR}$. The definitions of $\mathrm{BCR}$ were varied for different studies as shown in Table 4; this should be considered when comparing results among different studies.

MRI characterization of $\mathrm{PCa}$ as the most advanced imaging method has been assessed as a potential predictor of BCR as well: Park et al. (25) concluded that PI-RADS might be useful compared to other surgical parameters in 158 patients involved in the study; Tan et al. (26) found that only MRI-detected tumor volume was a significant predictor of BCR. Interestingly, and similar to our findings, PI-RADS v2 was found to be statistically insignificant on univariate analysis and was excluded from further multivariable analysis. Despite its limited contribution as a prognostic factor, mpMRI still remains a key role in $\mathrm{PCa}$ detection, staging, and characterization $(27,28)$.

In the present series, PCa-specific mortality is very low despite a relapse rate of $19 \%$ at a short median follow-up of 26.3 months. However, most biochemical relapses following radical prostatectomy will take place within the first 24 months of follow-up, and therefore, studies do give some window of observation. Information from USWE-measured tissue stiffness may potentially inform the decision to enroll patients with a high risk of BCR into clinical trials after considering other factors such as overall health and benefits of the interventions. Using the current data in combination with other clinicopathological factors, it is possible to identify patients at high risk of BCR following prostatectomy, and these men may need an aggressive approach using multimodality approach of combining hormones and chemotherapy particularly when the latter has already shown benefits in metastatic disease (29).

The current study has several limitations: firstly, this is a single institutional study and needs to be externally validated; the application of USWE in clinic still needs additional training and appropriate literature to support it (30). Secondly, there aren't many patients involved with low-risk disease buy may require a long follow-up to know biochemical outcomes. Lastly, as there are a significant number of high-risk patients in this study, a mean of 2 years of follow-up may cover the time period of early biochemical failure in these men, but long-term follow-ups are still needed.

Our findings in this study add to the existing knowledge and show that USWE has the potential ability in a wide clinical application field. This quantitative USWE imaging method may optimize treatment decisions for patients with localized PCa. Further studies are also needed to use this imaging method in accurately selecting cancer patients for adjuvant treatment following radical prostatectomy.

\section{DATA AVAILABILITY}

The datasets generated for this study are available on request to the corresponding author.

\section{ETHICS STATEMENT}

This study was carried out in accordance with the recommendations of the East of Scotland Research Ethics Committee 1 (13/ES/0099) and Research and Development (No. 
2012ON32) with written informed consent from all subjects. All subjects gave written informed consent in accordance with the Declaration of Helsinki. The protocol was approved by the East of Scotland Research Ethics Committee 1.

\section{AUTHOR CONTRIBUTIONS}

GN and $\mathrm{CW}$ contributed to the study conception and design. GN, CW, DU, MS-B, and SL contributed to

\section{REFERENCES}

1. Bolla $\mathrm{M}$, van Poppel $\mathrm{H}$, Collette L, van Cangh P, Vekemans K, Da Pozzo L, et al. Postoperative radiotherapy after radical prostatectomy: a randomised controlled trial (EORTC trial 22911). Lancet. (2005) 366:5728. doi: 10.1016/s0140-6736(05)67101-2

2. Collette L, Burzykowski T, Carroll KJ, Newling D, Morris T, Schröder FH. Is prostate-specific antigen a valid surrogate end point for survival in hormonally treated patients with metastatic prostate cancer? Joint Research of the European Organisation for Research and Treatment of Cancer, the Limburgs Universitair Centrum, and AstraZeneca Pharmaceuticals. J Clin Oncol. (2005) 23:6139-48. doi: 10.1200/jco.2005.08.156

3. Suardi N, Capitanio U, Chun FKH, Graefen M, Perrotte P, Schlomm T, et al. Currently used criteria for active surveillance in men with low-risk prostate cancer. Cancer. (2008) 113:2068-72. doi: 10.1002/cncr.23827

4. Mitterberger M, Horninger W, Aigner F, Pinggera GM, Steppan I, Rehder $\mathrm{P}$, et al. Ultrasound of the prostate. Cancer Imaging. (2010) 10:408. doi: 10.1102/1470-7330.2010.0004

5. Oehr P, Bouchelouche K. Imaging of prostate cancer. Curr Opin Oncol. (2007) 19:259-64. doi: 10.1097/CCO.0b013e3280ad439b

6. Sigrist RMS, Liau J, Kaffas AE, Chammas MC, Willmann JK. Ultrasound elastography: review of techniques and clinical applications. Theranostics. (2017) 7:1303-29. doi: 10.7150/thno.18650

7. Ahmad S, Cao R, Varghese T, Bidaut L, Nabi G. Transrectal quantitative shear wave elastography in the detection and characterisation of prostate cancer. Surg Endosc. (2013) 27:3280-7. doi: 10.1007/s00464013-2906-7

8. Bercoff J, Chaffai S, Tanter M, Sandrin L, Catheline S, Fink M, et al. In vivo breast tumor detection using transient elastography. Ultrasound Med Biol. (2003) 29:1387-96. doi: 10.1016/S0301-5629(03)00978-5

9. Bercoff J, Tanter M, Fink M. Supersonic shear imaging: a new technique for soft tissue elasticity mapping. IEEE Trans Ultrason Ferroelectr Freq Control. (2004) 51:396-409. doi: 10.1109/TUFFC.2004.1295425

10. Wei C, Jin B, Szewczyk-Bieda M, Gandy S, Lang S, Zhang Y, et al. Quantitative parameters in dynamic contrast-enhanced magnetic resonance imaging for the detection and characterization of prostate cancer. Oncotarget. (2018) 9:15997-6007. doi: 10.18632/oncotarget.24652

11. Wei C, Li C, Szewczyk-Bieda M, Upreti D, Lang S, Huang Z, et al. Performance characteristics of transrectal shear wave elastography imaging in the evaluation of clinically localized prostate cancer: a prospective study. $J$ Urol. (2018) 200:549-558. doi: 10.1016/j.juro.2018.03.116

12. Cookson MS, Aus G, Burnett AL, Canby-Hagino ED, D'Amico AV, Dmochowski RR, et al. Variation in the definition of biochemical recurrence in patients treated for localized prostate cancer: The American Urological Association Prostate Guidelines for Localized Prostate Cancer Update Panel Report and Recommendations for a Standard in the Reporting of Surgical Outcomes. J Urol. (2007) 177:540-5. doi: 10.1016/j.juro. 2006.10.097

13. Barentsz J, Richenberg J, Clements R, Choyke P, Verma S, Villeirs G, et al. ESUR prostate MR guidelines 2012. Eur Radiol. (2012) 22:74657. doi: 10.1007/s00330-011-2377-y

14. Fluss R, Faraggi D, Reiser B. Estimation of the Youden Index and its associated cutoff point. Biometrical J. (2005) 47:458-72. doi: 10.1002/bimj. 200410135 the acquisition of data. HM, SL, and SA analyzed the data. CW, YZ, and XZ interpreted the data. CW drafted the manuscript. YZ, HM, XZ, SA, DU, MS-B, and SL contributed to the revision. GN contributed to the critical revision.

\section{ACKNOWLEDGMENTS}

This study was supported by Prostate Cancer UK (PG12-39).

15. Boehm K, Salomon G, Beyer B, Schiffmann J, Simonis K, Graefen $\mathrm{M}$, et al. Shear wave elastography for localization of prostate cancer lesions and assessment of elasticity thresholds: implications for targeted biopsies and active surveillance protocols. J Urol. (2015) 193:794800. doi: 10.1016/j.juro.2014.09.100

16. Woo S, Kim SY, Cho JY, Kim SH. Shear wave elastography for detection of prostate cancer: a preliminary study. Korean J Radiol. (2014) 15:34655. doi: 10.3348/kjr.2014.15.3.346

17. Kattan MW, Eastham JA, Stapleton AMF, Wheeler TM, Scardino PT. A preoperative nomogram for disease recurrence following radical prostatectomy for prostate cancer. J Natl Cancer Inst. (1998) 90:766-71. doi: 10.1093/jnci/90.10.766

18. Kattan MW, Wheeler TM, Scardino PT. Postoperative nomogram for disease recurrence after radical prostatectomy for prostate cancer. J Clin Oncol. (1999) 17:1499-9. doi: 10.1200/jco.1999.17.5.1499

19. Cooperberg MR, Hilton JF, Carroll PR. The CAPRA-S score: a straightforward tool for improved prediction of outcomes after radical prostatectomy. Cancer. (2011) 117:5039-46. doi: 10.1002/cncr.26169

20. Cooperberg MR, Pasta DJ, Elkin EP, Litwin MS, Latini DM, DuChane J, et al. The UCSF Cancer of the Prostate Risk Assessment (CAPRA) Score: a straightforward and reliable preoperative predictor of disease recurrence after radical prostatectomy. J Urol. (2005) 173:1938-42. doi: 10.1097/01.ju.0000158155.33890.e7

21. Grossfeld GD, Latini DM, Lubeck DP, Mehta SS, Carroll PR. Predicting recurrence after radical prostatectomy for patients with high risk prostate cancer. J Urol. (2003) 169:157-63. doi: 10.1016/S0022-53 47(05)64058-X

22. Stephenson AJ, Scardino PT, Eastham JA, J.R. FJB, Dotan ZA, DiBlasio CJ, et al. Postoperative nomogram predicting the 10-year probability of prostate cancer recurrence after radical prostatectomy. J Clin Oncol. (2005) 23:700512. doi: $10.1200 /$ jco.2005.01.867

23. Ozden C, Aktas BK, Bulut S, Erbay G, Tagci S, Gokkaya CS, et al. Effect of age on biochemical recurrence after radical prostatectomy. Kaohsiung J Med Sci. (2017) 33:91-5. doi: 10.1016/j.kjms.2016.11.002

24. Freedland SJ, Aronson WJ, Terris MK, Kane CJ, Amling CL, Dorey F, et al. The percentage of prostate needle biopsy cores with carcinoma from the more involved side of the biopsy as a predictor of prostate specific antigen recurrence after radical prostatectomy. Cancer. (2003) 98:234450. doi: $10.1002 /$ cncr.11809

25. Park SY, Oh YT, Jung DC, Cho NH, Choi YD, Rha KH, et al. Prediction of biochemical recurrence after radical prostatectomy with PI-RADS version 2 in prostate cancers: initial results. Eur Radiol. (2016) 26:25029. doi: 10.1007/s00330-015-4077-5

26. Tan N, Shen L, Khoshnoodi P, Alcalá HE, Yu W, Hsu W, et al. Pathological and 3 Tesla volumetric magnetic resonance imaging predictors of biochemical recurrence after robotic assisted radical prostatectomy: correlation with whole mount histopathology. J Urol. (2018) 199:121823. doi: 10.1016/j.juro.2017.10.042

27. Ahmed HU, El-Shater Bosaily A, Brown LC, Gabe R, Kaplan R, Parmar $\mathrm{MK}$, et al. Diagnostic accuracy of multi-parametric MRI and TRUS biopsy in prostate cancer (PROMIS): a paired validating confirmatory study. Lancet. (2017) 389:815-22. doi: 10.1016/S0140-6736(16)32401-1

28. Dickinson L, Ahmed HU, Allen C, Barentsz JO, Carey B, Futterer JJ, et al. Magnetic resonance imaging for the detection, 
localisation, and characterisation of prostate cancer: recommendations from a European consensus meeting. Eur Urol. (2011) 59:47794. doi: 10.1016/j.eururo.2010.12.009

29. James ND, Sydes MR, Clarke NW, Mason MD, Dearnaley DP, Spears MR, et al. Addition of docetaxel, zoledronic acid, or both to first-line long-term hormone therapy in prostate cancer (STAMPEDE): survival results from an adaptive, multiarm, multistage, platform randomised controlled trial. Lancet. (2016) 387:1163-77. doi: 10.1016/S0140-6736(15)01037-5

30. Barr RG. Just because there is a button doesn't mean it is appropriate to use or that it will give accurate information. J Ultrasound Med. (2019) 38:1139. doi: $10.1002 /$ jum. 14990
Conflict of Interest Statement: The authors declare that the research was conducted in the absence of any commercial or financial relationships that could be construed as a potential conflict of interest.

Copyright (c) 2019 Wei, Zhang, Malik, Zhang, Alqahtani, Upreti, Szewczyk-Bieda, Lang and Nabi. This is an open-access article distributed under the terms of the Creative Commons Attribution License (CC BY). The use, distribution or reproduction in other forums is permitted, provided the original author(s) and the copyright owner(s) are credited and that the original publication in this journal is cited, in accordance with accepted academic practice. No use, distribution or reproduction is permitted which does not comply with these terms. 